\title{
Mannanase Production by Aspergillus niger USM F4 Via Solid Substrate Fermentation in a Shallow Tray Using Palm Kernel Cake as a Substrate
}

\author{
Syarifah $\underline{\text { Ab Rashid }}{ }^{1 *}$, Darah $\underline{\text { lbrahim }}^{1}$, and Ibrahim ${\underline{\text { Che } \text { Omar }^{2}}}^{2}$ \\ ${ }^{1}$ Industrial Biotechnology Research Laboratory (IBRL), School of Biological Sciences, Universiti Sains Malaysia, 11800 \\ Minden, Penang Malaysia. \\ ${ }^{2}$ Faculty of Agrolndustry and Natural Resources, Universiti Malaysia Kelantan, Karung Berkunci 36, 16100 Pengkalan \\ Chepa, Kelantan \\ E.mail: sar1603@yahoo.com
}

Received $4^{\text {th }}$ March 2012; Received in revised form $10^{\text {th }}$ June 2012; Accepted $13^{\text {th }}$ June 2012

\begin{abstract}
Aims: A local fungal isolate, Aspergillus niger USM F4 produced high level of mannanase activity when cultivated in a shallow tray system $\left(45 \times 40 \times 7 \mathrm{~cm}^{3}\right)$ using palm kernel cake $(P K C)$, an easily available cheap agricultural waste which are found abundantly in Malaysia.

Methodology and Results: A range of 0.25 to $1.5 \mathrm{~cm}$ bed heights were investigated in tracking in the most suitable condition and maximum production of mannanase. The highest mannanase production of $918.68 \mathrm{U} / \mathrm{g}$ substrate was obtained on the fifth day of cultivation after using all the optimised cultural conditions that consisted of $400 \mathrm{~g}$ of PKC that equivalent to $0.50 \mathrm{~cm}$ of substrate thickness with the particle size of $\leq 0.5 \mathrm{~mm}$, moisture content of $80 \%$ (w/w) with the addition of $2 \%(\mathrm{w} / \mathrm{w})$ molasses as a carbon source and $4 \%(\mathrm{w} / \mathrm{w})$ ammonium nitrate as a nitrogen source, inoculums size of $1 \times 10^{7}$ spores $/ \mathrm{ml}$, with once at every $24 \mathrm{~h}$ of mixing frequency and cultivation temperature at room temperature $30 \pm 2{ }^{\circ} \mathrm{C}$

Conclusion, significance and impact of study: The results obtained from this study showed that a shallow tray system was suitable to be used for getting highest enzyme production in SSF. Besides using a bigger volume of substrate, the correct substrate bed height is also important.
\end{abstract}

Keywords: Antigrowth, bio-factors, optical density, submerged fermentation

\section{INTRODUCTION}

Malaysia is an industrial based country and every year tonnes of agricultural wastes are accumulated, and these lignocellulosic rich materials are potentially to be used as substrate in solid substrate fermentation (SSF) for the production of enzymes and other microbial secondary metabolites. The SSF involves the growth and metabolism of microorganisms on moist solid in the absence or near absence of free flowing water. These fermentation systems which are closer to their natural habitats may prove more efficient in producing certain enzymes and metabolites. In fact SSF offers distinct advantages over submerged fermentation including simplicity of media, no complex machinery or equipments, no specific control systems, greater compactness of the fermentation vessel due to lower water volume, greater and superior product yields, low energy demand, economy of space, easier for scaling-up processes, smaller volume of solvent needed for product recovery and easier control of contamination due to low moisture level in SSF system (Jecu, 2000).

Mannanase exists in nature in two forms, as galactomannan and also as acetylated galactomannan. Galactomannan is present in the seed of leguminous plants and composed of a homogenous backbone of $\beta-1$ -
4 linked mannose residues, whereas acetylated galactomannan is a principal component of hemicelluloses that has a heterogenous backbone of $\beta-1-4$ linked mannose and glucose unit (Tamaru et al., 1995). Mannanases (EC 3.2.2.78 1,4- $\beta$-D-mannan mannanohydrolases) occur widely in microorganisms in bacteria, yeasts and fungi as well as from germinating seeds of terrestrial plants [Ferreira and Filho (2004), Heck et al. (2005), Jiang et al. 2006)]. However, production of mannanse by microorganisms is more promising due to its low cost, high yield and readily controlled conditions.

The objective of the present study is to optimize mannanase production by a local isolate, Aspergillus niger USM F4 via SSF using a shallow tray system with palm kernel cake (a waste from the palm oil industry which is inexpensive and abundantly available locally) as a substrate.

\section{MATERIALS AND METHODS}

The maintenance of fungal culture and spore suspension preparation

A locally isolated filamentous fungus, Aspergillus niger USM F4 was obtained from the stock cultures of Industrial 
Biotechnology Research Laboratory (IBRL). It was subcultured fortnightly on potato dextrose agar slants and stored at $4{ }^{\circ} \mathrm{C}$. The spore suspension was prepared by adding $5.0 \mathrm{~mL}$ of sterile distilled water into the agar slant containing mature fungal culture and shaking it vigorously. The spore suspension (stock) underwent a serial dilution process to obtain an inoculum size of $1 \times 10^{7}$ spores $/ \mathrm{mL}$. Haemocytometer slide chamber (Neubauer, Germany) was used to determine the spore number.

\section{Solid substrate fermentation and early profiling of mannanase production based on the bed height of PKC}

Palm kernel cake (PKC), a local agro-waste that was previously dried under the sunlight was applied as a sole substrate in this experiment. The initial cultural conditions and medium compositions parameters used were based on the previous report (Syarifah et al., 2011) where the optimisation were carried-out in a shake flask system with $5 \mathrm{~g}$ of PKC. However, in this study a shallow tray with the size of $45 \times 40 \times 7 \mathrm{~cm}$ was used. Before continuing with the SSF in a tray system, the bed height of the substrate in a tray needed to be determined first. Therefore, the amount of substrate of 200, 400, 800 and $1200 \mathrm{~g}$ which gave to $0.25,0.50,1.00$ and $1.50 \mathrm{~cm}$ of PKC bed height, respectively were studied. Then, each of the experiments was supplied with $80 \%(\mathrm{v} / \mathrm{w})$ moisture content, $1 \times 10^{7}$ spores $/ \mathrm{ml}$ of inoculum size, cultivation temperature at $30 \pm 2{ }^{\circ} \mathrm{C}, 0$ hour mixing frequency, with the addition of $2 \%$ $(\mathrm{w} / \mathrm{w})$ molasses as a carbon source and $4 \%(\mathrm{w} / \mathrm{w})$ ammonium nitrate as a nitrogen source. The cultivation was carried-out for 8 days and the mannanase activity, as well as fungal growth were determined at every $24 \mathrm{~h}$ intervals. All experiments were carried out in triplicates and the results were presented as mean of the triplicates experiments.

\section{Optimization of different cultural conditions towards mannanase production and fungal growth}

The optimisation of SSF system for mannanase production and fungal growth were performed based on the modification of cultural conditions (physical parameters) which were determined based on the modification of moisture content in the range of 60 to 120 $\%(\mathrm{v} / \mathrm{w})$, particle of substrate size $(\leq 0.5 \mathrm{~mm}$ to $2.0 \mathrm{~mm})$, inoculum sizes $\left(1 \times 10^{4}\right.$ to $1 \times 10^{8}$ spores $\left./ \mathrm{mL}\right)$, cultivation temperature $\left(25^{\circ} \mathrm{C}\right.$ to $\left.40{ }^{\circ} \mathrm{C}\right)$ and frequency of mixing (once at 0 to $48 \mathrm{~h}$ ). All experiments were carried out in triplicates and the results were presented as mean of the triplicates experiments.

\section{Enzyme extraction}

Mannanase was extracted by adding distilled water containing $0.1 \%(\mathrm{v} / \mathrm{v})$ of Tween 80 into the fermented PKC. The mixture was then mixed using a rotary shaker for $30 \mathrm{~min}$ at room temperature $\left(28 \pm 2{ }^{\circ} \mathrm{C}\right)$ and at the agitation speed of $150 \mathrm{rpm}$. The solid residue was separated from enzymatic solution by filtration through Whatman filter paper No.1. The filtrate was used as the mannanase source of enzyme.

\section{Determination of biomass component in fungal (glucosamine)}

A. niger USM F4 growth was examined by determining the glucosamine content of the fungus (Swift, 1972). The fermented sample was dried at $80{ }^{\circ} \mathrm{C}$ for a day. The glucosamine attendance was detected spectrophotometrically at $530 \mathrm{~nm}$ and the growth was expressed as $\mathrm{mg}$ glucosamine per $\mathrm{g}$ of substrate. Glucosamine powder was used as a standard.

\section{Determination of mannanase activity}

Mannanase activity was assayed by mixing $0.5 \mathrm{~mL}$ of an appropriately diluted enzyme solution with $0.5 \mathrm{ml}$ of $0.5 \%$ locust bean gum in $50 \mathrm{mM}$ citric acid-trisodium citrate buffer $(\mathrm{pH} \mathrm{4})$ at $60{ }^{\circ} \mathrm{C}$ for $30 \mathrm{~min}$. The reaction was stopped by the addition of $1.5 \mathrm{~mL}$ dinitrosalicylic acid (Miller, 1959). After 5 minute boiling, the amount of reducing sugars was determined spectrophotometrically at $575 \mathrm{~nm}$. Mannose was used as a standard (Lin and Chen, 2004). One unit of mannanase activity is defined as the amount of enzyme that releases $1 \mu \mathrm{mol}$ of mannose per minute under the assay conditions. Mannanase production was expressed as units (U) per gram of dry weight of PKC.

\section{RESULTS}

\section{Profiling of incubation period via different substrate thickness}

There were four substrate thickness or also known as substrate bed height tested for this system viz. 200, 400, 800 and $1200 \mathrm{~g}$ of PKC which gave to $0.25,0.50,1.00$ and $1.50 \mathrm{~cm}$, respectively. The results obtained are shown in Figure 1, where the highest mannanase production was achieved when substrate thickness of $0.50 \mathrm{~cm}$ or equivalent to $400 \mathrm{~g}$ of PKC was used in the tray system with about $903.62 \mathrm{U} / \mathrm{g}$ substrate mannanase activity. The second highest was when the $0.25 \mathrm{~cm}$ or equivalent to $200 \mathrm{~g}$ of PKC was used with $868.16 \mathrm{U} / \mathrm{g}$ substrate mannanase activity. Both of them achieved the highest mannanase production on the fifth day of cultivation. The $800 \mathrm{~g}$ and $1200 \mathrm{~g}$ of PKC that produced $1.00 \mathrm{~cm}$ and 1.50 $\mathrm{cm}$ substrate thickness produced about $671.07 \mathrm{U} / \mathrm{g}$ substrate and $474.92 \mathrm{U} / \mathrm{g}$ substrate, respectively on the seventh day of cultivation. The fungal growth obtained were $0.83,1.10,1.40$ and $1.10 \mathrm{mg}$ glucosamine $/ \mathrm{g}$ substrate from the substrate bed height of $0.25,0.500$, 1.00 and $1.50 \mathrm{~cm}$, respectively. The results obtained showed that the mannanase production was not growth dependant. Therefore, for the subsequent experiments, substrate amount of $400 \mathrm{~g}$ of PKC (0.50 cm thickness) was selected to be used and the cultivation was carried out for five days. 

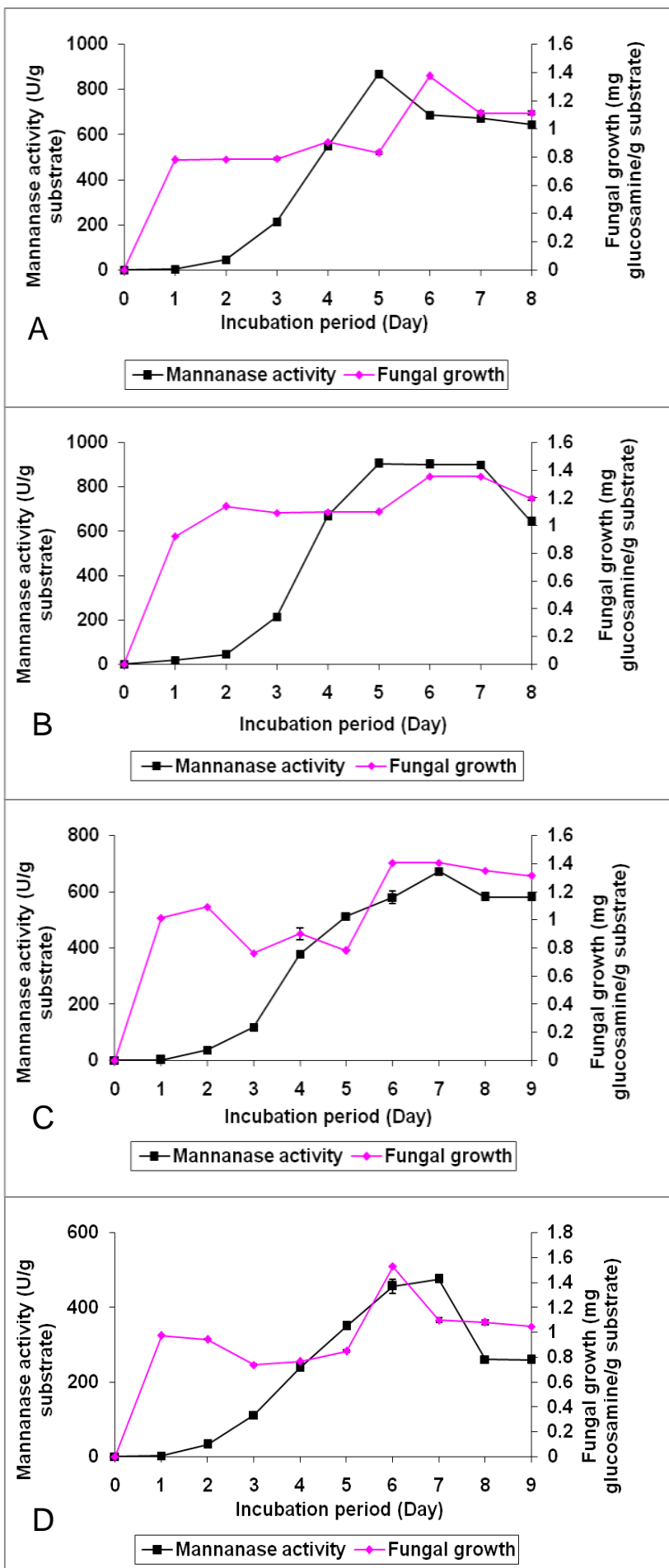

Figure 1: Effects of substrate thickness or bed height on mannanase production and fungal growth by $A$. niger USM F4. (A) $0.25 \mathrm{~cm}$ or equivalent to $200 \mathrm{~g}$ of PKC, (B) $0.50 \mathrm{~cm}$ or equivalent to $400 \mathrm{~g}$ of $\mathrm{PKC}$, (C) $1.00 \mathrm{~cm}$ or equivalent to $800 \mathrm{~g}$ of $\mathrm{PKC}$, (D) $1.5 \mathrm{~cm}$ or equivalent to $1200 \mathrm{~g}$ of PKC
Optimisation of cultural conditions for mannanase production and $\boldsymbol{A}$. niger USM F4 growth

Based on the initial profiling, the amount of substrate of $400 \mathrm{~g}$ which gave to $0.50 \mathrm{~cm}$ of substrate thickness was selected for further optimisation of cultural conditions and medium composition in a tray system. Since, these parameters play important roles in producing maximal mannanase production, the optimisation needs to be done.

Effect of moisture content: The effect of moisture content towards mannanase production was investigated and the results are shown in Figure 2. The moisture content added to the substrate was adjusted from 60-120 $\%(\mathrm{v} / \mathrm{w})$. The maximum mannanase production was observed at $80 \%(\mathrm{v} / \mathrm{w})$ with a final activity of $904.41 \mathrm{U} / \mathrm{g}$ substrate. The fungal growth obtained was $1.17 \mathrm{mg}$ glucosamine/g substrate. It was followed by the $100 \%$, $120 \%$ and $60 \%(\mathrm{v} / \mathrm{w})$ moisture content which produced $870.94,819.81$ and $775.22 \mathrm{U} / \mathrm{g}$ substrate, respectively. As for the fungal growth, they were about $1.19,1.24$ and 1.16 $\mathrm{mg}$ glucosamine/g substrate, respectively.

Effect of substrate size: Figure 3 shows the effect of substrate size towards mannanase production. The results showed that this tray system required substrate size of $\leq 0.5 \mathrm{~mm}$ rather than other particle sizes (1.0, 1.5 and $2.0 \mathrm{~mm}$ ). The production of mannanase obtained was $906.00 \mathrm{U} / \mathrm{g}$ substrate and the achieved fungal growth was $1.22 \mathrm{mg}$ glucosamine/g substrate. On the other hand, the substrate size of $1.0,1.5$ and $2.0 \mathrm{~mm}$ produced 818.03 $\mathrm{U} / \mathrm{g}$ substrate, $817.43 \mathrm{U} / \mathrm{g}$ substrate and $781.76 \mathrm{U} / \mathrm{g}$ substrate, whilst the fungal growth produced were 1.21, 1.15 and $1.10 \mathrm{mg}$ glucosamine/g substrate, respectively. A suitable particle size $(\leq 0.5 \mathrm{~mm})$ was used in the subsequent experiments.

Effect of inoculum sizes: The tested spore suspension ranged of $1 \times 10^{4}$ to $1 \times 10^{8}$ spores $/ \mathrm{mL}$. The result of the enzyme productivity was denoted in Figure 4. As observed, $1 \times 10^{7}$ spores $/ \mathrm{mL}$ gave the best mannanase production with $914.86 \mathrm{U} / \mathrm{g}$ substrate and $1.19 \mathrm{mg}$ glucosamine/g substrate of fungal growth. It was followed by the inoculum sizes of $1 \times 10^{8}, 1 \times 10^{6}, 1 \times 10^{5}$ and $1 \times 10^{4}$ spores $/ \mathrm{ml}$ which produced about $908.02,865.00,814.79$ and $557.40 \mathrm{U} / \mathrm{g}$ substrate of mannanase, whilst the fungal growth obtained were $1.34,1.18,1.18$ and $1.17 \mathrm{mg}$ glucosamine/g substrate, respectively.

Effect of cultivation temperature: Temperature played a more prominent role in SSF than submerged fermentation. The net temperature in SSF system is influenced not only by the environmental temperature, but also by the increase in temperature generated from the metabolic activities of the fungi growing on the solid substrates (Pang et al., 2006). Most of microorganism used in SSF was mesophilic, thus the optimal temperature for growth is between 20 to $40{ }^{\circ} \mathrm{C}$ and maximum growth is usually below $50{ }^{\circ} \mathrm{C}$ (Manpreet et al., 2005). Figure 5 depicted 


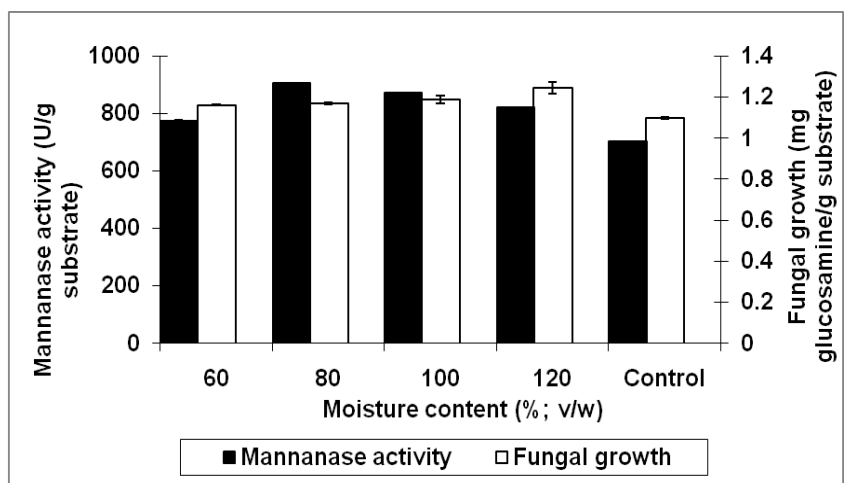

Figure 2: Production of mannanase on different moisture contents by $A$. niger USM F4. $80 \%(\mathrm{v} / \mathrm{w})$ of moisture content marked the highest mannanase activity although the fungal growth was low

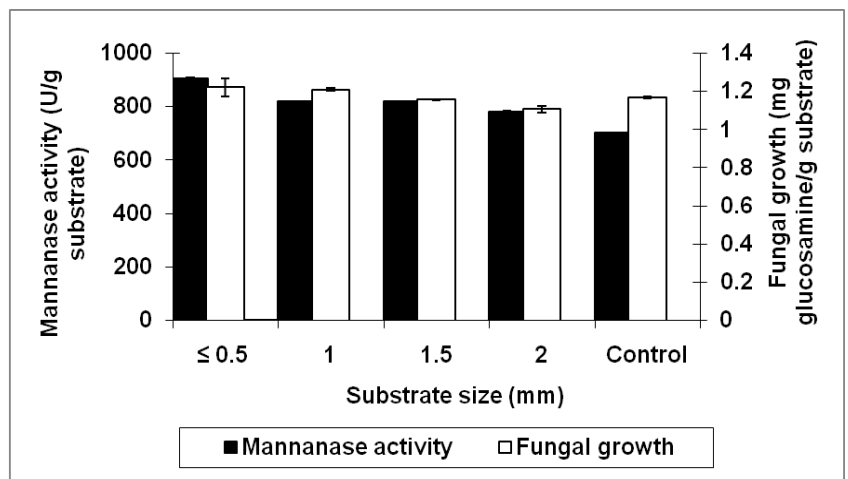

Figure 3: The PKC size of $\leq 0.5 \mathrm{~mm}$ indicated the best performance compared to $1,1.5$ and $2 \mathrm{~mm}$ sizes

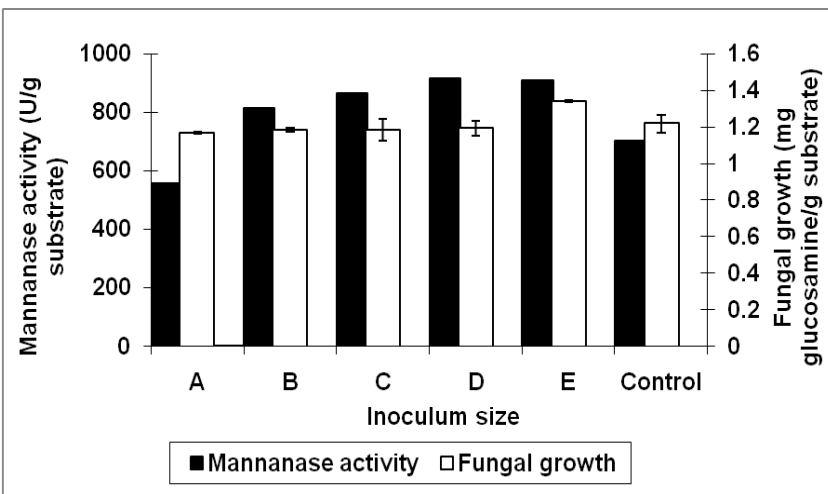

Figure 4: A gradual activity difference was shown prior to inoculum sizes allowed $1 \times 10^{7}$ spore $/ \mathrm{mL}$ to be the preferred size for mannanase production in SSF

(Indicator: A: $1 \times 10^{4}$, B: $1 \times 10^{5}$, C: $1 \times 10^{6}$, D: $1 \times 10^{7}$, E: 1 $\times 10^{8}$ spores $/ \mathrm{mL}$ )

that mannanase gave the best production at temperature of $30 \pm 2{ }^{\circ} \mathrm{C}$ for a tray system. The productivity obtained was $916.30 \mathrm{U} / \mathrm{g}$ substrate and fungal growth of $1.21 \mathrm{mg}$ glucosamine/g substrate. Other temperatures $(25,35$ and $40{ }^{\circ} \mathrm{C}$ ) also showed good production result with about
898.07, 901.24 and $900.45 \mathrm{U} / \mathrm{g}$ substrate, whilst for fungal growth, each temperature produced $1.20,1.36$ and 1.17 $\mathrm{mg}$ glucosamine/g substrate, respectively.

Effect of mixing frequency: Frequency of substrate mixing for once at every 24 hours became the best condition for mannanase production in a tray system. An appropriate mixing or agitation can lead to a better production by controlling the heat accumulation during fermentation. As shown in Figure 6, the maximum production obtained was $916.33 \mathrm{U} / \mathrm{g}$ substrate and the fungal growth was $1.22 \mathrm{mg}$ glucosamine/g substrate. Frequency of mixing for once at every $48 \mathrm{~h}$ also indicated good mannanase result with $837.59 \mathrm{U} / \mathrm{g}$ substrate and fungal growth of $1.34 \mathrm{mg}$ glucosamine/g substrate. It was followed by once at 0 and $12 \mathrm{~h}$ mixing frequency which produced $815.59 \mathrm{U} / \mathrm{g}$ substrate (fungal growth of $1.34 \mathrm{mg}$ glucosamine/g substrate) and $749.51 \mathrm{U} / \mathrm{g}$ substrate (fungal growth of $1.16 \mathrm{mg}$ glucosamine/g substrate), respectively.

Profile after cultural conditions optimisation in a tray system for mannanase production: A profile after the optimisation of cultural conditions was carried out for eight days. Figure 7 unequivocally indicated that the final productivity achieved from a tray system was $918.68 \mathrm{U} / \mathrm{g}$ substrate and fungal growth of $1.21 \mathrm{mg}$ glucosamine $/ \mathrm{g}$ substrate. The maximum production was achieved on the five days of cultivation time. Not much increment was observed for optimisation before and after cultural conditions (only $1.67 \%$ increments) and no correlation was observed between enzyme production and fungal growth for both profiles.

\section{DISCUSSION}

Tray fermenter is one of the simplest fermenter for SSF system and usually made of wood, metal and plastic. Tray fermenter in SSF can be arranged one above the other with suitable amounts of gaps between them. The trays are then placed in a fermentation chamber with a controlled humid atmosphere. Tray fermenters have always been used by the traditional food-processing industries especially in the making of miso, tempeh and koji for soy sauce manufacturing. The tray fermenter is the most suitable fermenter for SSF application in lignocellulolytic enzyme production, as it permits better oxygen into the substrate bed, due to the thin layer of the substrate (Couto et al., 2001). Parameters such as temperature, mixing frequency and moisture content are crucial in obtaining optimum results via SSF. Their levels are usually determined by carrying out optimisation study. In this study SSF was used for efficient mannanase production by $A$. niger USM F4 in a tray fermenter with $\mathrm{PKC}$ as the solid substrate.

Bed height is important in SSF as fungal growth on the surface of substrate was almost similar, but the growth within the bed height varied depending on the substrate thickness or also known as the bed height. This 


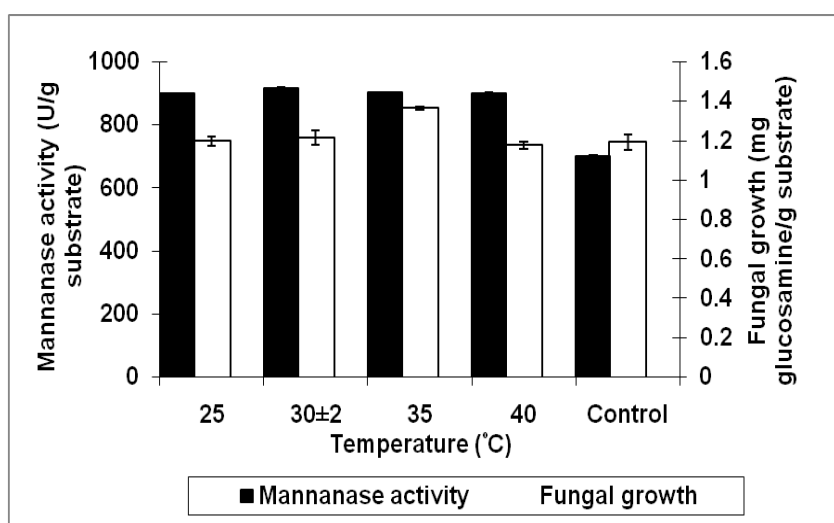

Figure 5: The range of ambient temperature used gave most appropriated access for $A$. niger USM F4 to produce mannanase as it almost similar to its original terrestrial

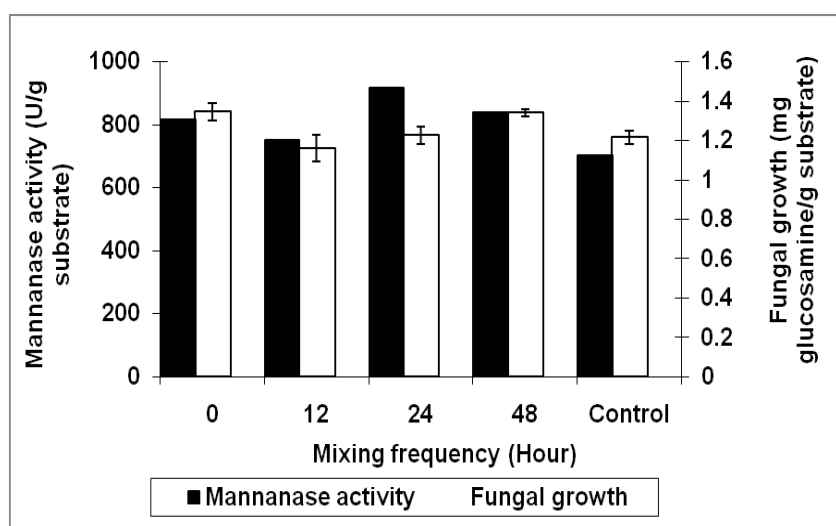

Figure 6: The $24 \mathrm{~h}$ mixing progress granted an optimum aeration in this system permitted the best mannanase activity after all

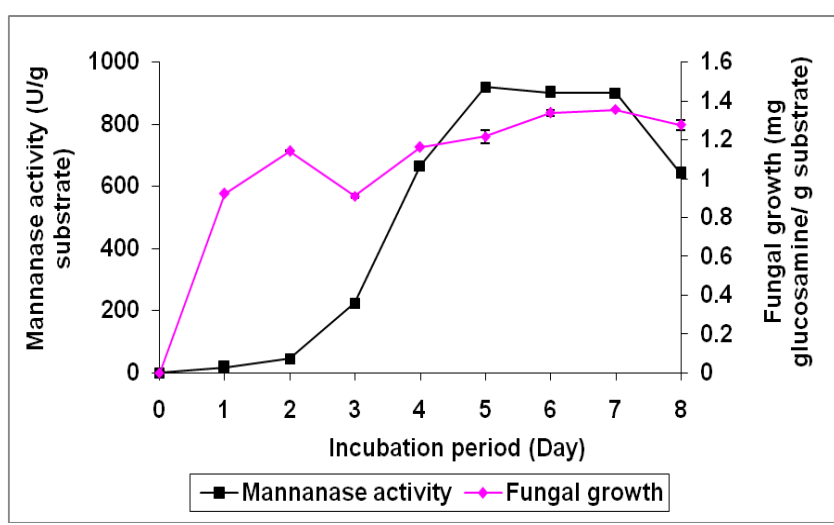

Figure 7: A time course production after cultural conditions optimisation depicted the maximum production of mannanase maintained at day five. The production was slightly dwindle until day eight

observation was initially attributed to heat generated by the fungal fermentation process which must be removed, since its growth is sensitive to temperature rise. It is further suggested that heat is better dissipated from the surface than from within the bed, and a thinner bed height allows for better heat removal than a thicker bed height. The differences in fungal growth for different bed height were not strongly attributed to heat effects alone (Annuar et al., 2010). There was also difficulty in achieving homogenous spatial distribution of aqueous solutions of nutrients added to the bed due to physical characteristics of the solid substrate and the bed thickness. This resulted in spatial gradient within the bed in terms of nutrient availability to the fungus. There was the existence of nutrient spatial gradient in the form of strong interaction between supplemented nutrient level and bed height. As the bed height increases, the ability to evenly distribute the nutrient compound and aqueous solution into the thickness of solid substrate bed becomes highly critical. Therefore, whether solid substrate bed becomes thicker, efficient mixing of nutrient solution into the bed is a vital process requirement regardless of the level of nutrient supplied. This is to avoid creating a nutrient gradient on and within the solid bed.

PKC is a tropical agro-industrial product of palm oil industry. The fruit of the palm tree (Elaeis guineensis) contains kernel which are processed for the extraction of oil. The solid residue left after oil extraction process constitutes PKC, which generally contains about $12-18 \%$ crude fiber and 15-18 \% crude protein (Darah and Ibrahim, 2009). A variety of microorganisms including bacteria, yeast, fungi and actinomycetes are capable of producing mannanases. However, filamentous fungi have been of great interest to researchers due to their efficiency in producing enzymes including mannanases. PKC offers potential advantages for the filamentous fungi compared to bacteria and yeasts. The existence of hyphal mode and turgor pressure at the tip of mycelium allows a power to proliferate, colonize and penetrate into the hardest part of solid substrate (Ramachandran et al., 2004). This condition directly permits the fungi to utilize the available nutrients in the solid substrates. Besides that, the filamentous fungi are also capable to tolerate low water activity and secrete hydrolytic enzymes.

Since SSF deals with the biological processes in which microorganisms grows on solid material with limited moisture level, moisture content of the substrate is also a crucial factor which drastically influences the fermentation process (Pandey et al., 2001). As shown in this study, the production of mannanase was poor at moisture level lower or higher than $80 \%(\mathrm{w} / \mathrm{w})$. The low level of moisture content leads to the reduction of substrate swelling, solubility of solid substances, nutrient diffusion and also prevented the nutrient absorption from the substrate. These facts result in insufficient nutrient supply by microorganism, which in turn causes the reduction in microbial growth and enzyme production (Venkateswarlu et al., 2000) and sometimes caused higher water retention. Although, a rise in moisture up to optimum level $(80 \%)$ enhances mannanse production, too high level of initial moisture content had unfavourable effect on mannanase production (Ikasari and Mitchell, 1994). 
The adverse effect of high moisture level on mannanase production might be attributed to the reduction of substrate porosity which directly leads to oxygen transfer limitation and increased chances for bacterial contamination (Perez-Guerra et al., 2003). Furthermore, low heat and mass transmission through the culture and the decrease of air exchange, can result in the decrease of microbial growth and product formation (Venkateswarlu et al., 2000). The multiplicity of optimum moisture content could be due to the fact that optimum moisture greatly depends on the water-binding characteristics of the substrate, temperature and selected microorganism. Hence, varying conditions provide different optimum moisture for microorganisms.

The SSF is an exothermic process where temperature directly influences the growth of microorganisms and product formation. The study showed that the increase of cultivation temperature higher than the optimum level $\left(30 \pm 2{ }^{\circ} \mathrm{C}\right)$ led to the reduction of mannanase yield. The decrease of mannanase production following the rise in cultivation temperature can be attributed to the adverse effect of high temperature on microbial growth and metabolic activities, resulting in the reduction of enzyme production by fungi (Venkateswarlu et al., 2000). The net temperature in SSF system is influenced not only by the environmental temperature but also by the increasing temperature generated from the metabolic activities of the fungi growing on the solid substrates (Pang et al., 2006).

Most microorganisms used in SSF are mesophilic and thus, the optimum temperatures for their growth is between $20-40{ }^{\circ} \mathrm{C}$ (Manpreet et al., 2005). Therefore, the temperature can be varied during the growth cycle (Mitchell et al., 2006). According to (Lee, 2010) the total incubation temperature in substrate bed can be higher than the original as the temperature gradient can be extra $20 \%$. This condition may directly lead to the accumulation of heat and demolish the desired product formed. Temperature of $30{ }^{\circ} \mathrm{C}$ has been proved as the best temperature in enzymatic synthesizing. In our case, $30 \pm 2$ ${ }^{\circ} \mathrm{C}$ is the room temperature and by using this temperature we can save on the energy cost. The diversity of optimum cultivation temperature can partially be explained by the fact that the effect of other process parameters such as moisture content of substrate, air flow and oxygen level on the environmental temperature, following growth temperature.

The size of substrate particles affected the extension and rate of microbial colonization, penetration, carbon dioxide removal and downstream extraction. The optimum particle size often represents a compromise between the accessibility of nutrients and the availability of oxygen (Manpreet et al., 2005). Smaller particle size will provide a large area for microbial attack but if it is too small, it will cause agglomeration and will weaken the fungal growth. Bigger particle allowed a better aeration (caused by increment of inter particle spaces) in SSF but it limited the attacking area of microbes (Couto and Sanromán, 2006).
Fungi endured a contact between hyphae and substrate via its hyphal growth. The outbreak of this parameter revealed that increment or decrement of spore amount will give a big impact towards cell growth which was commonly caused by the competition among cells in getting nutrients from the medium. Low inoculum size influenced the time extension for cell proliferation to utilize substrate and produced the desired product (Ramachandran et al., 2004). This problem can be observed at inoculums size of $1 \times 10^{4}$ spores $/ \mathrm{mL}$ that produced the lowest mannanase production. On the other hand, higher inoculums size induces cell production, biomass synthesis and shortened the lag phase during fungal growth. Hence, the cultivation period can be reduced.

Microbial activity of anaerobic cultures is markedly affected by the air supply to the system. There are varying aspects of aeration function in SSF processes including maintenance of oxygen supply and removing carbon dioxide from the system, heat transfer and the control of moisture level. The results of this study showed that aeration rate by mixing frequency improved the production of mannanase. The favorable effect of air flow on mannanase production could be attributed to the enhancement of product formation by microorganism under-forced aeration. The optimum mixing frequency obtained from the present study was once at every $24 \mathrm{~h}$. These variations in optimum level of mixing frequency can be related to the selected of microorganism, the particular amount of oxygen for product synthesis, the level of heat evolution to be removed, the quantity of carbon dioxide and other volatile metabolites which would be dissipated, the thickness of substrate bed height and also the volume of pore space in the substrate.

Commonly, oxygen can be accessed at the surface area of the substrate particle but certain cases demanded a mixing program to reach the gas mostly if there was bed height interference in the system. But bear in mind that the mixing frequency, especially with a short time gap, is capable to destroy the fungal mycelia. Even though mixing can significantly improve heat removal (mostly via reactor wall), it is not used in all solid substrate reactors because not all fungi and solid substrate can tolerate the shear and collision forces that resulted from mixing (Hamidi-Esfahani et al., 2004). Only suitable mixing frequency can be applied for aeration purpose. Other than heat removal, aeration is also important to provide oxygen for cell growth, wash out the carbon dioxide and moisture transfer between solids and gas phase (Raimbault, 1998).

\section{CONCLUSION}

The present study had proven that shallow tray system was suitable to be used in SSF for mannanase production using a bigger volume of substrate. The correct bed height size or substrate thickness is important, and together with the other optimised conditions, highest enzyme production can be achieved. 


\section{ACKNOWLEDGEMENTS}

The authors would like to thank the Intensive Research Priority Area (IRPA) grant from Ministry of Science, Technology and The Environment Malaysia for its financial support. A special appreciation for Professor Darah Ibrahim, Professor Ibrahim Che Omar, lab mates, staffs of biological sciences for their infallible supports.

\section{REFERENCES}

Annuar, M. S. M., Murthy, S. M. and Sabaratnam, V. (2010). Laccase production from oil palm industry solid wastes: statistical optimization of selected process parameters. Engineering Life Sciences 10(1): 40-48.

Couto, S. R. and Sanromán, M. A. (2006). Application of solid-state fermentation to food industry-A review. Journal of Food Engineering 76 (3): 291-302.

Couto, S. R., Domínguez, A. and Sanromán, A. (2001). Utilisation of lignocellulosic wastes for lignin peroxidase production by semi-solid-state cultures of Phanerochaete chrysosporium, Biodegradation 12: 283-289.

Darah, I. and Ibrahim, C. O. (2009). Concept in Microbiology. Penerbit Universiti Sains Malaysia. pp. 193-195.

Ferreira, H. M. F. and Filho, E.X.F. (2004). Purification and characterization of a $\beta$-mannanase from Trichoderma harzianum starin T4. Carbohydrate Polymers 57: 23-29.

Hamidi-Esfahani, Z., Shojaosadatia, S. A. and Rinzema, A. (2004). Modelling of simultaneous effect of moisture and temperature on Aspergilus niger growth in solid-state fermentation. Biochemical Engineering Journal 21: 265-272.

Heck, J. X., de Barros Soares, L. H. and Ayub, M. A. Z. (2005). Optimization of xylanase and mannanase production by Bacillus circulans Strain BL53 on solid state fermentation. Enzyme and Microbial Technology 37: 417-423.

Ikasari, L. and Mitchell, D. A. (1994). Protease production by Rhizopus oligosporus in solid state fermentation. Applied Microbiology and Biotechnology 10: 320 - 324.

Jecu, L., (2000). Solid state fermentation of agricultural wastes for endoglucanase production. Industrial Crops and Products 11: 1-5.

Jiang, Z., Wei, Y., Li, D., Li, L., Chai, P. and Kusakabe, I. (2006). High level production, purification and characterization of a thermostable $\beta$-mannanase from a newly isolated Bacillus subtilis WY34. Carbohydrate Polymers 66: 88-96.

Lee, C. K. (2010). Development of solid state fermentation system for enzyme production and its use in a pilot scale deinking of wastepaper. Thesis of Philosophy Doctor, Universiti Sains Malaysia.

Lin, T. C. and Chen, C. (2004). Enhanced mannanase production by submerged culture of Aspergillus niger $\mathrm{NCH}-189$ using defatted copra based media. Process
Biochemistry 39: 1103-1109.

Manpreet, S., Sawraj, S., Sachin, D., Pankaj, S. and Banerjee, U.C. (2005). Review article: Influence of process parameters on the production of metabolites in solid state fermentation. Malaysian Journal of Microbiology 1(2): 1-9.

Miller, G. L. (1959). Use of dinitrosalicylic acid reagent for determination of reducing sugar. Analytical Chemistry 34: 426-428.

Mitchell, D. A., Krieger, N. and Berovič, M. (2006). Solid state fermentation bioreactors: Fundamental of design and operation. Springer-Verlag Berlin Heidelberg. pp. 3.

Pandey, A., Soccol, C. R. and Mitchell, D. (2001). New developments in solid state fermentation: Ibioprocesses and products. Process Biochemistry 35 (10): 1153-1169.

Pang, P. K., Darah, I., Poppe, L., Szakacs, G. and Ibrahim, C.O. (2006). Xylanase production by a local isolate, Trichoderma sp. FETL c3-2 via solid state fermentation using agricultural wastes as substrates. Malaysian Journal of Microbiology 2(1): 7-14.

Perez-Guerra, N., Torrado-Agrasar, A., Lopez-Macias, C. and Pastrana, L. (2003). Main characteristics and applications of solid substrate fermentation. Electronic Journal of Environment, Agriculture, Food and Chemical 2(3): 343-350.

Raimbault, M. (1998). General and microbiological aspects of solid substrate fermentation. Electronic Biotechnology 1: 1-15.

Ramachandran, S., Patel, A. K., Nampoothiri, K. M., Francis, F., Nagy, V., Szakacs, G. and Pandey, A. (2004). Coconut oil cake-a potential raw material for the production of $\alpha$ - amylase. Bioresource Technology 93(2): 169-174.

Swift, M. J. (1972). The estimation of mycelial biomass by determination of the hexosamine content of wood tissue decayed by fungi. Soil Biology and Biochemistry 5: 321-332.

Syarifah, A. R., Darah, I. and. Ibrahim, C. O. (2011). Utilization of palm kernel cake for the production of mannanase by an indigenous filamentous fungus, Aspergillus niger USMF4 under solid substrate fermentation. Internet Scientific Publications 9 (1).

Tamaru, Y., Araki, T., Amagoi, H., Mori, H. and Morishita, T. (1995). Purification and characterization of an extracellular $\beta-1,4-$ mannanase from a marine bacterium Vibrio sp. Strain MA-138. Applied and Environmental Microbiology 61: 4454-4458.

Venkateswarlu, G., Krishna, P. S., Pandey, A. and Rao, L.V. (2000). Evaluation of Amycolatopsis mediterranei VA18 for production of rifamycin-B. Process Biochemistry 37: 331-338. 